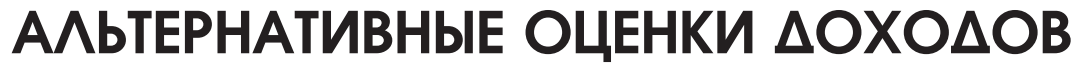 НАСЕАЕНИЯ В РЕГИОНАХ РОССИИ
}

\begin{abstract}
А.В. Янцен
Янцен Андрей Викторович - аспирант. Новосибирский государственный университет, ул. Пирогова, 2, Новосибирск, Россия, 630090. E-mail: andreyjanzenx@gmail.com.

Величина среднедушевых доходов является одним из основных показателей уровня жизни населения. Данный показатель широко используются в исследованиях, посвященных бедности, межрегиональному неравенству по доходам, а также является основным ориентиром успешности проводимой региональной политики. Ряд исследователей отмечают низкое качество официальных данных по доходам населения и ставят под сомнение их достоверность в некоторых регионах России. К основным причинам этого относят значительные масштабы теневой экономики, особенно на уровне некоторых регионов, недостаточное финансирование исследований со стороны государства, а также устаревшие статистические методы обработки данных. В работе предлагается метод проверки качества официальных статистических данных по душевым доходам при помощи ряда косвенных показателей. Применение данного метода также позволяет получить альтернативные оценки среднедушевых доходов населения в регионах страны. На основе данных за 2013-2014 гг. показано, что в ряде регионов официальная статистическая оценка доходов, вероятно, существенно (более чем на 20\%) занижена. Полученные альтернативные оценки среднедушевых доходов могут быть использованы в дальнейших исследованиях вместо официальных показателей.
\end{abstract}

Альтернативная оценка, доход на душу населения, косвенный показатель, регионы Pоссии.

DOI: $\underline{10.14530 / \mathrm{se} .2017 .1 .052-070}$

\section{ВВЕДЕНИЕ}

Величина среднедушевого дохода - один из основных показателей, отражающих уровень жизни. Статистические данные по доходам на душу населения широко используются в исследованиях, посвященных межрегиональному неравенству и вопросам бедности, которые являются первостепенными. К большому сожалению, в современной российской статистике существует ряд нерешенных проблем, которые сказываются на качестве официальных данных. Многие исследователи отмечают крайне низкое ка-

(C) Янцен А.В., 2017 
чество статистики доходов и уровня жизни, особенно в региональном разрезе $[1 ; 2 ; 5 ; 12]$. Среди причин, как правило, фигурируют высокий уровень теневой экономики, масштабы которой варьируются по регионам, методические проблемы обработки данных, а также отсутствие должного финансирования исследований со стороны государства [5].

Одним из способов, который позволяет осуществить сопоставление уровней жизни между регионами, не используя при этом показатель дохода, является сравнение регионов по накопленному имуществу [6; 14]. Этот компонент благосостояния дает возможность учесть теневые доходы, что крайне важно для нашей страны. Изначально этот метод использовался для международных сопоставлений, а в качестве показателя уровня жизни выступала обеспеченность легковыми автомобилями в личной собственности (количество автомобилей на тысячу человек). Однако, как будет показано далее, в применении к российским регионам такой подход может привести к неверным результатам.

В таком случае встает вопрос: можно ли в качестве индикатора уровня жизни и доходов населения использовать какие-либо другие косвенные показатели, по которым большинство регионов сопоставимы? Существование таких косвенных характеристик доходов позволит на практике отобрать регионы, в которых официальные данные могут не соответствовать действительности. А если дополнительно предположить, что между косвенным показателем и доходами в регионе имеется функциональная зависимость, которая одинакова для большинства регионов, то это позволит скорректировать официальные данные по доходам с учетом значений косвенного показателя.

Похожий метод широко распространен в налоговой практике. Если имеются основания полагать, что руководство предприятия скрывает часть доходов, то косвенно указать на это могут счета за коммунальные услуги. Например, если было заявлено о простое предприятия, но при этом наблюдаются высокие значения по потребляемой электроэнергии, воды или газа, то это является поводом для более тщательной проверки. Если заявленный объем выпущенной продукции существенно ниже объемов использованных для нее упаковочных материалов, то это также может служить сигналом о наличии на предприятии скрытого производства и, соответственно, неучтенных доходов. Если удается подтвердить факт недостоверности показателя доходов, то происходит переоценка показателя по аналогии со сходными предприятиями, либо расчетным методом, исходя из прироста дохода на единицу косвенного показателя.

В данной работе предложен метод, который позволяет верифицировать официальные статистические оценки доходов в регионах России с помо- 
щью косвенных показателей, которые, по предположению, должны эти доходы характеризовать. Исходя из того, что статистические оценки доходов существенно отклоняются от действительных величин только в ряде регионов, мы предполагаем, что для остальных регионов эти оценки достаточно точны (достоверны). Косвенные же показатели изначально рассматриваются нами как точные, достоверные статистические оценки, так как основные причины искажения оценок доходов, о которых речь пойдет ниже, влияют на них в гораздо меньшей степени.

\section{ОБСУЖДЕНИЕ В ЛИТЕРАТУРЕ}

Большинство работ (напр.: [1; 2; 5; 15]), в которых затрагивается вопрос достоверности данных по доходам в России, посвящены либо описанию методологических неточностей, которые допускает Росстат, либо перечислению возможных причин искажения официальных данных по доходам. Так, Н.В. Зубаревич в качестве основных причин искажения официальных данных по доходам выделяет следующие [5].

Неточности, обусловленные объективными трудностями сбора информации. Сюда в первую очередь следует отнести недостаточный объем выборки (проблема репрезентативности) при обследованиях бюджетов домашних хозяйств (ОБДХ). Так, число респондентов в некоторых регионах может составлять всего 300-500 чел., что иногда приводит к неожиданным скачкам показателя в течение года.

Большие масштабы теневой экономики. Данный фактор крайне важно учитывать на региональном уровне. По данным Росстата, в большинстве регионов Южного и Северо-Кавказского федеральных округов доля легальной заработной платы варьируется от 11 до 33\%. Для сравнения, в северных ресурсодобывающих регионах данная величина составляет 59-83\%, а в среднем по стране - 41\% [5]. Для получения сопоставимых данных по доходам Росстат проводит их корректировку с учетом масштабов теневой экономики в регионе.

Методические проблемы. Росстат использует механизм дооценки данных, полученных в результате ОБДХ. Дооценка проводится с учетом объемов розничной торговли и платных услуг в регионе, а также обмена валюты [5]. Данный способ приводит, по мнению Н.В. Зубаревич, к систематическому завышению доходов москвичей, так как существенная часть розничной торговли в Москве относится к жителям Подмосковья и гостям столицы.

Влияние институциональных факторов. К данному пункту можно отнести как воздействие меняющихся норм и правил, так и попытки исказить картину жизни в регионе со стороны хозяйствующих субъектов. 
Разделяя эту точку зрения, некоторые авторы зачастую делают выводы о достоверности или, соответственно, о недостоверности статистических оценок доходов, опираясь на значения каких-либо иных показателей, которые косвенно характеризуют уровень жизни в регионе. Например, та же Н.В. Зубаревич в качестве такого косвенного показателя использует уровень автомобилизации (количество собственных автомобилей на тысячу человек) [14]. Население региона с более высоким количеством автомобилей на тысячу человек должно обладать, по ее мнению, и более высоким доходом. Здесь неявно автор предполагает, что форма связи между доходами и уровнем автомобилизации одинакова для всех регионов, что обеспечивает их межрегиональную сопоставимость. Однако это не всегда так, например, вследствие институциональных и географических различий между регионами, а также из-за того, что далеко не всегда личный автомобиль эксплуатируется по месту его регистрации. При международных сопоставлениях, откуда и был заимствован данный подход, влияние этих факторов гораздо слабее, чем при региональных. Еще одним недостатком в рассуждениях Н.В. Зубаревич является тот факт, что она не задается вопросом о функциональном виде зависимости между доходами населения и уровнем автомобилизации. В такой ситуации любые выводы о недостоверности низких величин официальных статистических оценок доходов в регионах, где они сопровождаются большим относительным количеством автомобилей, кажутся сомнительными.

Данная работа развивает идею Н.В. Зубаревич и других отечественных экономистов (в частности, $[1 ; 2 ; 12 ; 15]$ ) относительно анализа достоверности официальной статистики доходов населения. Ее новизна состоит в разработке метода количественного анализа, который позволяет проверить достоверность данных о доходах и получить их альтернативные оценки, основываясь на значениях косвенных показателей.

\section{МЕТОД ВЕРИФИКАЦИИ СТАТИСТИЧЕСКИХ ОЦЕНОК ДОХОДОВ}

Рабочая гипотеза состоит в следующем. Для каждого региона страны существует ряд косвенных показателей, которые тесно связаны с величиной среднедушевого дохода в данном регионе. В большинстве регионов связь между отдельным косвенным показателем и величиной дохода имеет один и тот же функциональный вид. Регионы, для которых данная связь нарушена, имеют специфические особенности, влияющие на косвенный показатель; если же таковых особенностей нет, то можно сделать вывод о недостаточной достоверности официальных оценок доходов в данных регионах.

Под тесной связью между косвенным показателем и величиной дохода 
подразумевается наличие логической взаимосвязи между ними, которая подтверждается эмпирическими данными (высокой степенью корреляции).

Функциональный вид связи между косвенным показателем и величиной дохода представляет собой уравнение парной регрессии, где величина дохода выступает в качестве регрессора.

Регионы, в которых происходит нарушение связи, представляют собой, с эконометрической точки зрения, влиятельные наблюдения в регрессии отдельного косвенного показателя по величине дохода.

На практике далеко не всегда можно судить о наличии или отсутствии региональных особенностей, которые могут нарушать связь между отдельным косвенным показателем и величиной среднедушевого дохода (как в случае показателя автомобилизации). По этой причине для верификации официальных оценок следует использовать некоторый ряд разноплановых косвенных показателей, чтобы уменьшить влияние неучтенных региональных особенностей.

Метод верификации статистических оценок доходов включает несколько этапов. На первом этапе, исходя из принятой рабочей гипотезы, происходит отбор множества косвенных показателей, которые тесно связаны с величиной среднедушевых доходов в регионе. Для каждого показателя рассчитывается величина его корреляции с доходами населения в регионах РФ.

На втором этапе осуществляется поиск функциональной связи между отобранными косвенными показателями и величиной среднедушевого дохода путем оценки уравнения парной регрессии. Косвенный показатель выступает в качестве зависимой переменной, а величина дохода - в качестве регрессора. Результатом второго этапа является множество уравнений регрессии, соответствующих каждому косвенному показателю.

Tретий этаn - поиск «сомнительных» регионов, т. е. регионов, которые являются влиятельными наблюдениями для отдельного уравнения регрессии. Данные регионы являются «сомнительными» в том смысле, что в них велика вероятность наличия региональных особенностей, влияющих на отдельный косвенный показатель, либо искажений статистических оценок доходов. На этом этапе производится также исключение «сомнительных» регионов из выборки.

На четвертом этапе оценивается уравнение регрессии по новой выборке (без «сомнительных» регионов). Предсказанные регрессией значения (fitted values) используются в качестве альтернативных оценок душевых доходов. В итоге будет получен набор таких альтернативных оценок, соответствующих отдельным косвенным показателям.

Пятый этап - получение итоговых альтернативных оценок душевых доходов в регионах РФ путем взятия взвешенного арифметического средне- 
го всех альтернативных оценок, полученных на четвертом этапе. В качестве весов выступают коэффициенты корреляции между величиной дохода и отдельным косвенным показателем, рассчитанные по выборке без «сомнительных» регионов.

Сравнение полученных итоговых альтернативных оценок с официальными статистическими оценками душевых доходов позволит выделить ряд регионов, в которых наблюдается значительное расхождение между официальной и альтернативной оценкой. Если более детальный анализ не выявляет наличие особых региональных условий, которые могли повлиять на исследуемую связь по большинству косвенных показателей, то можно сделать вывод, что в данных регионах имеет место недостаточная достоверность официальных данных о среднедушевых доходах.

\section{РЕЗУЛЬТАТЫ АНАЛИЗА}

Анализ выполнялся по данным за 2013 и 2014 гг. Пространственная выборка охватывает 83 субъекта Российской Федерации. Нужно отметить, что данные по Архангельской и Тюменской областям охватывают также входящие в эти области автономные округа, которые, таким образом, учитываются дважды: как таковые и в составе включающих их областей. Источники исходных данных - Центральная база статистических данных (ЦБСД), Единая межведомственная информационно-статистическая система (ЕМИСС), а также официальный сайт Центрального банка России.

Исходный набор показателей, косвенно характеризующих душевой доход в регионе, приведен в таблице 1. В первую очередь это тарифы на услуги, которые не являются объектом регулирования на местном или федеральном уровне. А поскольку услуги не являются мобильным благом (т. е. потребляются только в месте производства), то тарифы на них складываются под воздействием исключительно внутрирегиональных предложения и спроса, спрос же в существенной степени определяется доходами населения. То же можно отнести и к ценам на жилье. Кроме того, в набор включено несколько других показателей (в частности, финансовые), величины которых потенциально могут быть обусловлены доходами населения. Последний столбец таблицы содержит обозначения переменных, соответствующих данным косвенным показателям, которые будут использоваться в дальнейшем.

Эмпирическая проверка наличия (и силы) связи между выбранными косвенными показателями и величиной среднедушевых доходов дала результаты, показанные в таблице 2. Она содержит результаты расчета для каждого косвенного показателя величины его корреляции с доходом. 
Косвенные показатели дохода и их описание

\begin{tabular}{|c|c|c|c|}
\hline Косвенный показатель & Описание & $\begin{array}{l}\text { Источник } \\
\text { данных }\end{array}$ & $\begin{array}{l}\text { Обозначение } \\
\text { переменной }\end{array}$ \\
\hline $\begin{array}{l}\text { Средняя цена квадрат- } \\
\text { ного метра жилья }\end{array}$ & $\begin{array}{l}\text { Средняя цена на вторичном } \\
\text { рынке жилья квадратного метра } \\
\text { в квартире среднего качества } \\
\text { (типовой) }\end{array}$ & Росстат & Home \\
\hline $\begin{array}{l}\text { Средняя цена аренды } \\
\text { квартиры у частных лиц }\end{array}$ & $\begin{array}{l}\text { Средняя цена аренды, вычис- } \\
\text { ленная по данным для одно- и } \\
\text { двухкомнатных квартир } \\
\end{array}$ & Росстат & Arenda \\
\hline $\begin{array}{l}\text { Первичный консульта- } \\
\text { тивный осмотр больно- } \\
\text { го у стоматолога }\end{array}$ & $\begin{array}{l}\text { Средняя стоимость одного по- } \\
\text { сещения }\end{array}$ & Росстат & Dentist \\
\hline Общий анализ крови & $\begin{array}{l}\text { Средняя стоимость одного } \\
\text { анализа }\end{array}$ & Росстат & Blood \\
\hline Ужин в ресторане & $\begin{array}{l}\text { Средняя цена ужина в ресторане } \\
\text { (включая спиртные напитки) на } \\
\text { одного человека }\end{array}$ & Росстат & Dinner \\
\hline $\begin{array}{l}\text { Вклады (депозиты) } \\
\text { физических лиц }\end{array}$ & $\begin{array}{l}\text { Средняя величина депозита на } \\
\text { одного человека (был проведен } \\
\text { пересчет показателя с учетом ве- } \\
\text { личины постоянного населения) }\end{array}$ & $\begin{array}{l}\text { Центральный } \\
\text { банк РФ }\end{array}$ & Deposit \\
\hline $\begin{array}{l}\text { Задолженность физи- } \\
\text { ческих лиц по креди- } \\
\text { там, предоставленным } \\
\text { кредитными организа- } \\
\text { циями }\end{array}$ & $\begin{array}{l}\text { Средняя величина задолжен- } \\
\text { ности по кредитам на одного че- } \\
\text { ловека (был проведен пересчет } \\
\text { показателя с учетом величины } \\
\text { постоянного населения) } \\
\end{array}$ & $\begin{array}{l}\text { Центральный } \\
\text { банк РФ }\end{array}$ & Debt \\
\hline $\begin{array}{l}\text { Оборот розничной } \\
\text { торговли }\end{array}$ & $\begin{array}{l}\text { Средняя величина оборота } \\
\text { розничной торговли на душу } \\
\text { населения }\end{array}$ & Росстат & Trade \\
\hline $\begin{array}{l}\text { Средняя цена посеще- } \\
\text { ния парикмахерской }\end{array}$ & $\begin{array}{l}\text { Средняя (для мужчин и женщин) } \\
\text { стоимость модельной стрижки }\end{array}$ & Росстат & Haircut \\
\hline $\begin{array}{l}\text { Обеспеченность на- } \\
\text { селения собственными } \\
\text { легковыми автомоби- } \\
\text { лями }\end{array}$ & $\begin{array}{l}\text { Количество автомобилей } \\
\text { на } 1000 \text { чел. населения }\end{array}$ & Росстат & Auto \\
\hline
\end{tabular}

Корреляция косвенных показателей и душевого дохода

\begin{tabular}{c|c|c|c|c|c|c|c|c|c|c}
\hline \multirow{2}{*}{$\begin{array}{c}\text { Коэффициент } \\
\text { корреляции }\end{array}$} & \multicolumn{10}{c}{ Переменная } \\
\cline { 2 - 20 } & Home & Arenda & Dentist & Blood & Dinner & Deposit & Debt & Trade & Haircut & Auto \\
\hline 2013 & 0,65 & 0,84 & 0,72 & 0,58 & 0,69 & 0,74 & 0,70 & 0,70 & 0,81 & 0,15 \\
\hline 2014 & 0,69 & 0,84 & 0,71 & 0,60 & 0,72 & 0,62 & 0,69 & 0,67 & 0,81 & 0,13 \\
\hline
\end{tabular}

Как видно из таблицы 2, корреляция между относительным количеством автомобилей и доходами в регионе оказалась наименьшей среди всех косвенных показателей. Это говорит об очень слабой линейной связи между 
доходами и уровнем автомобилизации. Наиболее коррелирована с душевыми доходами стоимость аренды квартиры у частных лиц. Объяснения достаточно очевидны. В России предложение в этой сфере ограничено и растет очень медленно, весьма слабо реагируя на спрос. Объемы предложения арендного жилья в расчете на душу населения в большинстве регионов, по грубой оценке, достаточно близки. Поэтому арендная плата в значительной мере определяется платежеспособностью арендаторов в регионе, т. е. доходами населения региона. Вторая причина в том, что регионы с высокими доходами являются наиболее привлекательными для миграции населения. Переселение людей приводит к увеличению спроса на жилье в регионе, что находит отражение как в стоимости аренды квартиры, так и в ценах на жилье. Сильную корреляцию с доходом имеет также средняя цена услуг парикмахера. Отчасти это можно объяснить тем, что, как правило, парикмахеры имеют сдельную форму оплаты труда. В таком случае в регионах с более высокими душевыми доходами больший доход парикмахеров достигается за счет более высокой стоимости их услуг. Для остальных косвенных показателей объяснение полученных связей также не составляет труда. Высокую корреляцию для медицинских услуг (посещение стоматолога и анализ крови) можно объяснить так же, как в случае услуг парикмахера. Для финансовых показателей (средние размеры депозита и остатка по кредиту для физических лиц) объяснение тривиально: более высокие доходы позволяют больше сберегать и больше занимать. Большие доходы в регионе также способствуют развитию розничной торговли, что отражается в росте ее объемов. Наиболее дорогие рестораны в нашей стране также находятся в наиболее обеспеченных регионах. Стоит отметить, что корреляция, рассчитанная для разных периодов, принимает практически одни и те же значения, что должно привести к схожим результатам.

Функциональная связь между каждым косвенным показателем и величиной среднедушевых доходов предполагается линейной. Теоретическое уравнение регрессии, описывающее такую связь, имеет вид

$$
X_{i}=\alpha+\beta M_{i}+\varepsilon_{i}
$$

где $i$ - индекс региона $(i=1, \ldots, 83), X_{i}$ - косвенный показатель в регионе $i$, $M_{i}$ - душевой доход в регионе $i, \varepsilon_{i}$ - остаток регрессии, $\alpha$ и $\beta$ - оцениваемые параметры регрессии (они, естественно, различны для разных косвенных показателей, однако, чтобы не загромождать обозначения, индекс показателя опущен).

Для того чтобы определить наблюдения («сомнительные» регионы), для которых рассматриваемая связь нарушается, находилось множество влиятельных наблюдений, с использованием расстояния Кука (Cook’s distance) 
[16-18]. Величина порогового значения принята равной 1. В результате был получен набор из 10 уравнений регрессий (для каждого года), по одному для каждого косвенного показателя. Для каждого уравнения регрессии рассчитывалось расстояние Кука и формировалось множество «сомнительных» регионов. Результаты представлены в таблицах 3 и 4.

Таблииа 3

Функциональная связь и «сомнительные» регионы по данным за 2013 г.

\begin{tabular}{l|c|c|c|c}
\hline $\begin{array}{c}\text { Пере- } \\
\text { менная }\end{array}$ & $\alpha$ & $\beta$ & $\begin{array}{c}\text { Коэффициент } \\
\text { детерминации } R^{2}\end{array}$ & $\begin{array}{c}\text { «Сомнительные» } \\
\text { регионы }\end{array}$ \\
\hline Home & $19555(3856)$ & $1,16(0,15)$ & 0,42 & $\begin{array}{c}\text { Москва, } \\
\text { Ямало-Ненецкий АО }\end{array}$ \\
\hline Arenda & $3544(749)$ & $0,41(0,03)$ & 0,71 & Ямало-Ненецкий АО \\
\hline Dentist & $20(15)$ & $0,006(0,001)$ & 0,52 & Ненецкий АО \\
\hline Blood & $130(16)$ & $0,004(0,001)$ & 0,34 & - \\
\hline Dinner & $915(82)$ & $0,3(0,03)$ & 0,48 & Ямало-Ненецкий АО \\
\hline Deposit & $-29033(11457)$ & $4,38(0,45)$ & 0,54 & Москва, Ненецкий АО \\
\hline Debt & $19081(4969)$ & $1,70(0,20)$ & 0,48 & Ханты-Мансийский АО \\
\hline Trade & $66971(8857)$ & $3,03(0,35)$ & 0,49 & Москва, Ненецкий АО \\
\hline Haircut & $106(17)$ & $0,008(0,001)$ & 0,66 & ЧАО \\
\hline Auto & $244(16)$ & $0,0009(0,001)$ & 0,02 & ЧАО
\end{tabular}

Примечание. В скобках указаны стандартные отклонения; все оценки, кроме $\beta$, при переменной Auto значимы на уровне 1\%, последняя не значима.

Таблииа 4

Функциональная связь и «сомнительные» регионы по данным за 2014 г.

\begin{tabular}{l|c|c|c|c}
\hline $\begin{array}{c}\text { Пере- } \\
\text { менная }\end{array}$ & $\alpha$ & $\beta$ & $\begin{array}{c}\text { Коэффициент } \\
\text { детерминации } R^{2}\end{array}$ & «Сомнительные» регионы \\
\hline Home & $17543(3948)$ & $1,25(0,15)$ & 0,48 & $\begin{array}{c}\text { Москва, Ямало-Ненецкий } \\
\text { АО, Ненецкий АО }\end{array}$ \\
\hline Arenda & $3360(793)$ & $0,41(0,03)$ & 0,71 & - \\
\hline Dentist & $15(19)$ & $0,006(0,001)$ & 0,50 & Ненецкий АО \\
\hline Blood & $141(18)$ & $0,004(0,001)$ & 0,35 & - \\
\hline Dinner & $923(87)$ & $0,3(0,03)$ & 0,52 & Ямало-Ненецкий АО \\
\hline Deposit & $-10300(14809)$ & $3,82(0,53)$ & 0,38 & Москва, Ненецкий АО \\
\hline Debt & $25473(5595)$ & $1,75(0,20)$ & 0,48 & - \\
\hline Trade & $66971(8857)$ & $3,03(0,35)$ & 0,49 & Ненецкий АО, ЧАО \\
\hline Haircut & $113(17)$ & $0,007(0,001)$ & 0,66 & ЧАО \\
\hline Auto & $234(19)$ & $0,0009(0,001)$ & 0,02 & ЧАО \\
\hline
\end{tabular}

В итоге в группу «сомнительных» регионов попали: Москва, Ямало-Ненецкий АО, Ненецкий АО, а также Ханты-Мансийский АО и ЧАО. Это свидетельствует о том, что в данных регионах либо присутствуют региональные особенности, влияющие на косвенные показатели, либо официальные данные по душевым доходам существенно отклоняются от действительно- 
сти. Также видно, что функциональные связи практически одинаковы для двух годов.

Душевые доходы в остальных регионах, которые можно считать репрезентативными (или почти репрезентативными) по болышинству косвенных показателей, должны хорошо описываться уравнением регрессии, если из исходной выборки убрать влиятельные наблюдения («сомнительные» регионы).

После исключения из исходной выборки «сомнительных» регионов были оценены парные регрессии величины душевого дохода по каждому косвенному показателю:

$$
M_{i}=\delta+\gamma X_{i}+\varepsilon_{i},
$$

где $i$ - индекс региона $(i=1, \ldots, 83), X_{i}$ - косвенный показатель в регионе $i$, $M_{i}$ - душевой доход в регионе $i, \varepsilon_{i}$ - остаток регрессии, $\delta$ и $\gamma$ - оцениваемые параметры регрессии.

После этого рассчитывались предсказанные регрессией величины дохода (fitted values) по j-му косвенному показателю. Они представляют собой точки, лежащие на линии регрессии при данных величинах дохода: $\hat{M}_{i j}=\hat{\delta}+\hat{\gamma} X_{i j}$, где $\hat{\delta}, \hat{\gamma}$ - оцененные значения коэффициентов регрессии, а $i$-индекс региона $(i=1, \ldots, 83)$. Данную величину назовем альтернативной оценкой душевого дохода по $j$-му косвенному показателю. Для всех косвенных показателей были рассчитаны коэффициенты корреляции со среднедушевым доходом по выборке без «сомнительных» регионов. В качестве итоговой альтернативной оценки душевых доходов принято взвешенное арифметическое среднее альтернативных оценок по всем косвенным показателям, где весами являются коэффициенты корреляции, рассчитанные по выборке без «сомнительных» регионов:

$$
\hat{M}_{i}=\frac{\sum_{j} w_{j} \hat{M}_{i j}}{\sum_{j} w_{j}},
$$

где $w_{j}$ - коэффициент корреляции $j$-го косвенного параметра с душевым доходом.

\section{АНАЛИЗ РЕЗУЛЬТАТОВ}

На основе проведенного анализа все регионы были разделены на три группы. В первую группу включены регионы, в которых альтернативная оценка доходов отличается от официальной не более чем на 10\%. В этих регионах официальные данные о душевых доходах практически совпадают с оценкой, полученной на основе косвенных показателей. Всего таких регионов - 44 для 2013 г. и 46 для 2014 г. 
Вторая группа состоит из регионов, в которых различия официальных и альтернативных оценок заключены в пределах 10-20\% (рuc. 1 и 2). Всего за 2013 г. было выделено 24 таких региона, а за 2014 г. - 22.

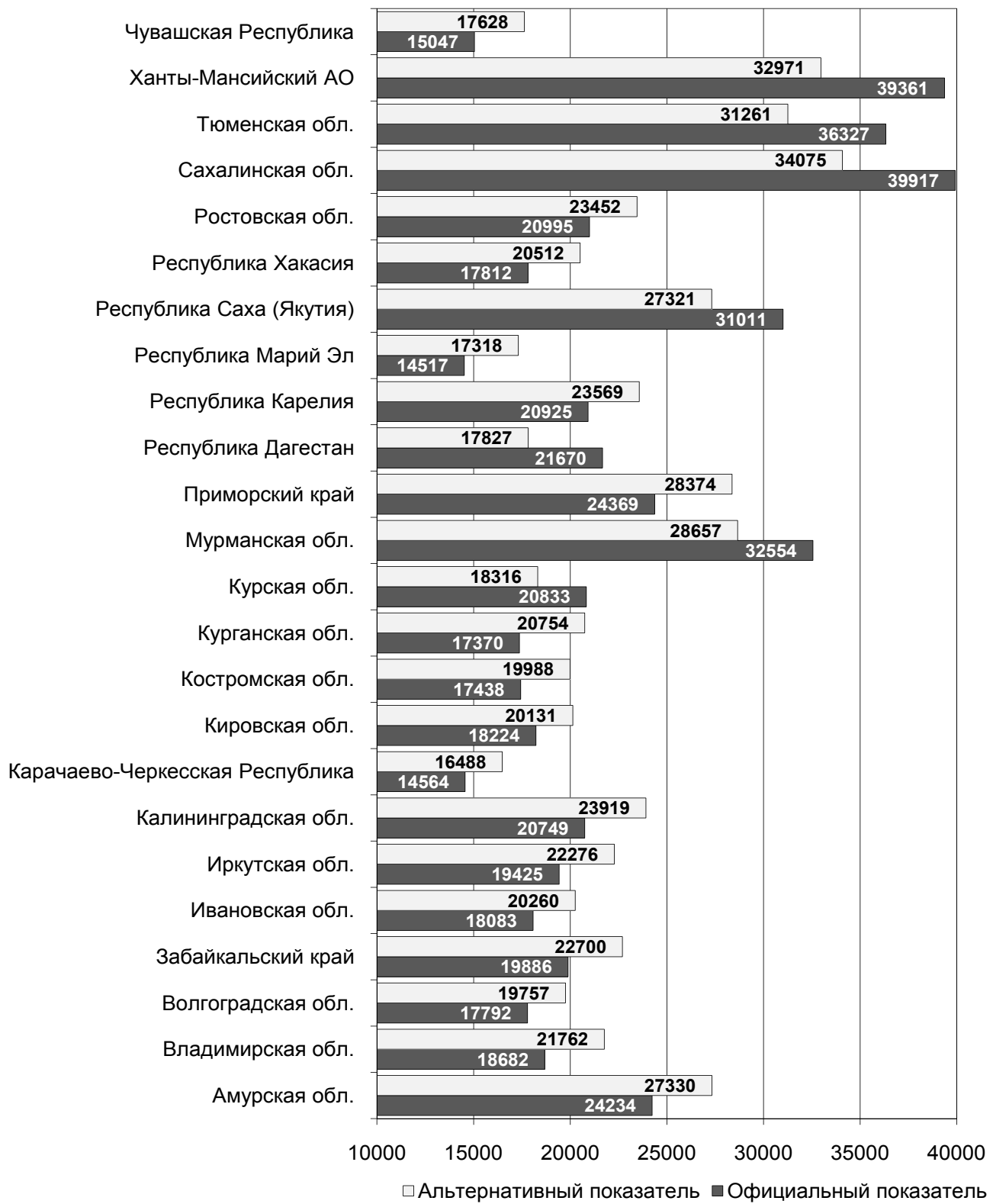

Puc.1. Альтернативная и официальная оценки дохода за 2013 г. для регионов второй группы, руб. 
Здесь собраны регионы, где официальные оценки доходов находятся «на грани достоверности», и потому к ним следует относиться с осторожностью.

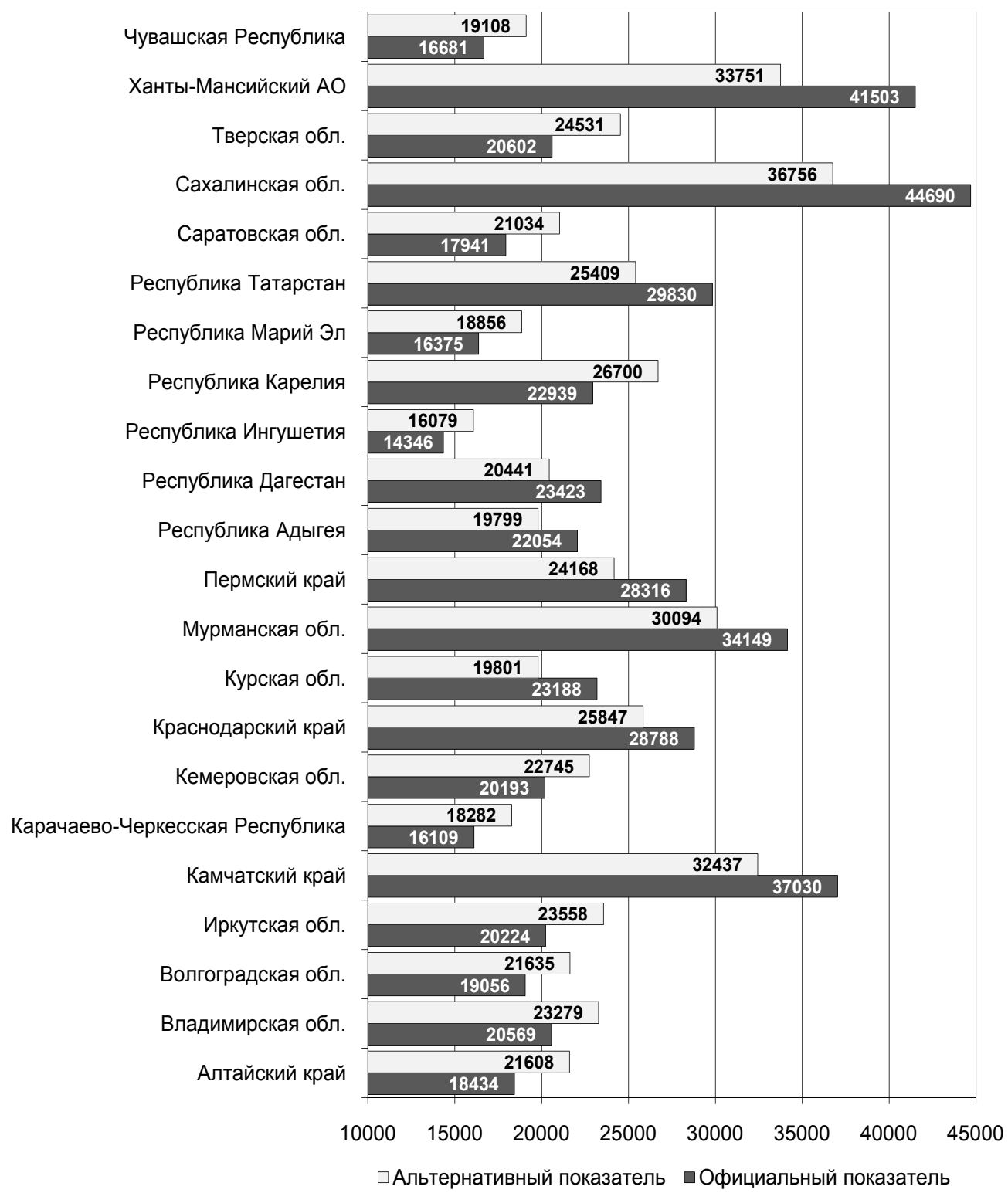

Рuc.2. Альтернативная и официальная оценки дохода за 2014 г. для регионов второй группы, руб. 
Оставшиеся регионы, у которых официальные показатели отличаются от альтернативных более чем на $20 \%$, составляют третью группу. Всего таких регионов 15, как для 2013 г., так и для 2014 г. (рис. 3 и 4)․․

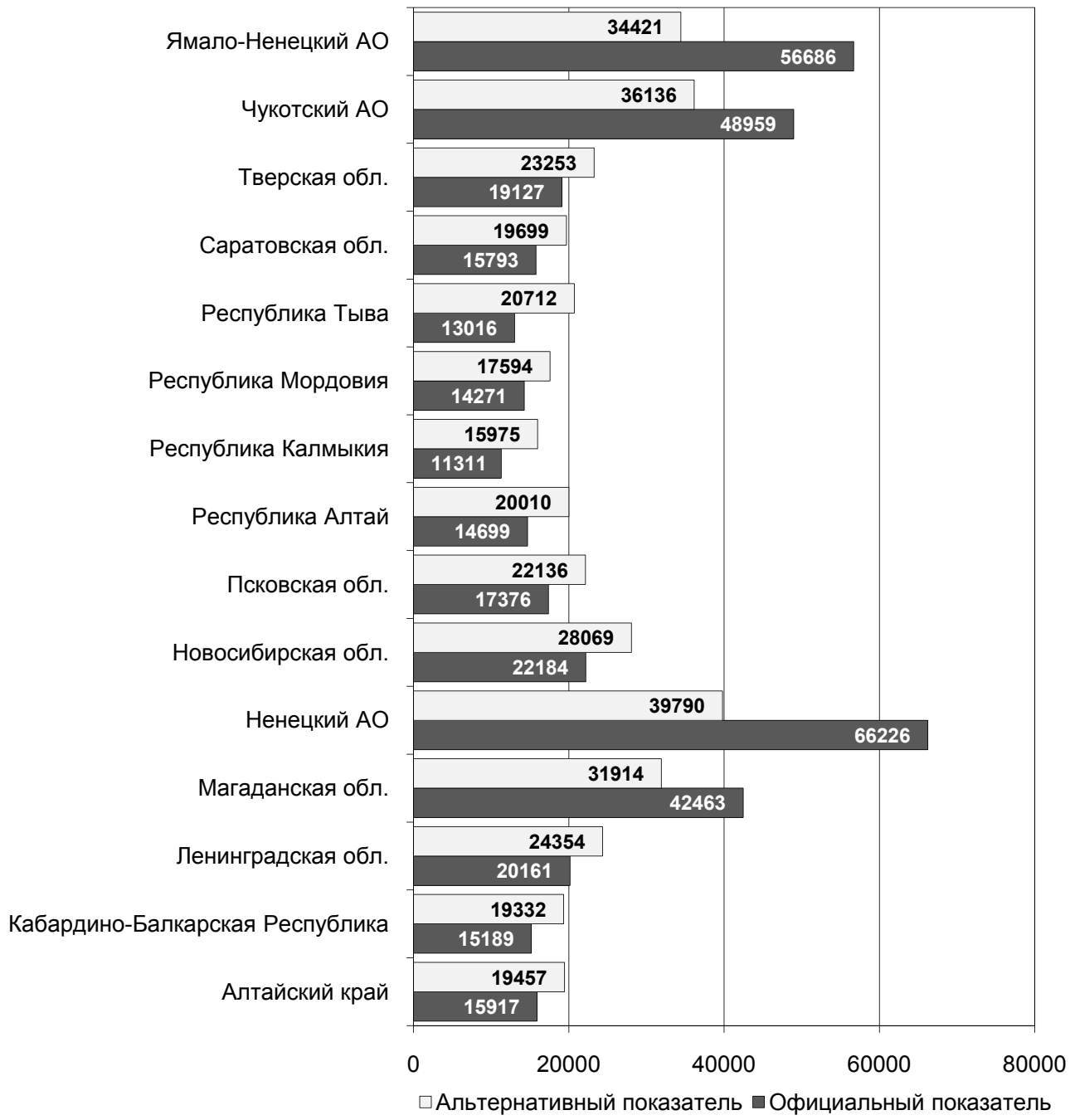

Puc.3. Альтернативная и официальная оценки дохода за 2013 г. для регионов третьей группы, руб.

${ }^{1}$ Корреляция и коэффициенты регрессий оказались практически одинаковыми для 2013 и 2014 гг., что свидетельствует о постоянстве составов каждой группы регионов. Так как автором делается акцент на группу «сомнительных» регионов, основной состав которых сохраняется (12 из 15 регионов), то в дальнейших работах предполагается оценить, по каким именно косвенным показателям существуют значительные расхождения с общей картиной по стране. 
Официальные данные по этим регионам заслуживают наиболее пристального внимания, поскольку именно здесь происходит наибольшее нарушение связи между величиной дохода на душу населения и значениями региональных косвенных показателей, которые его характеризуют.

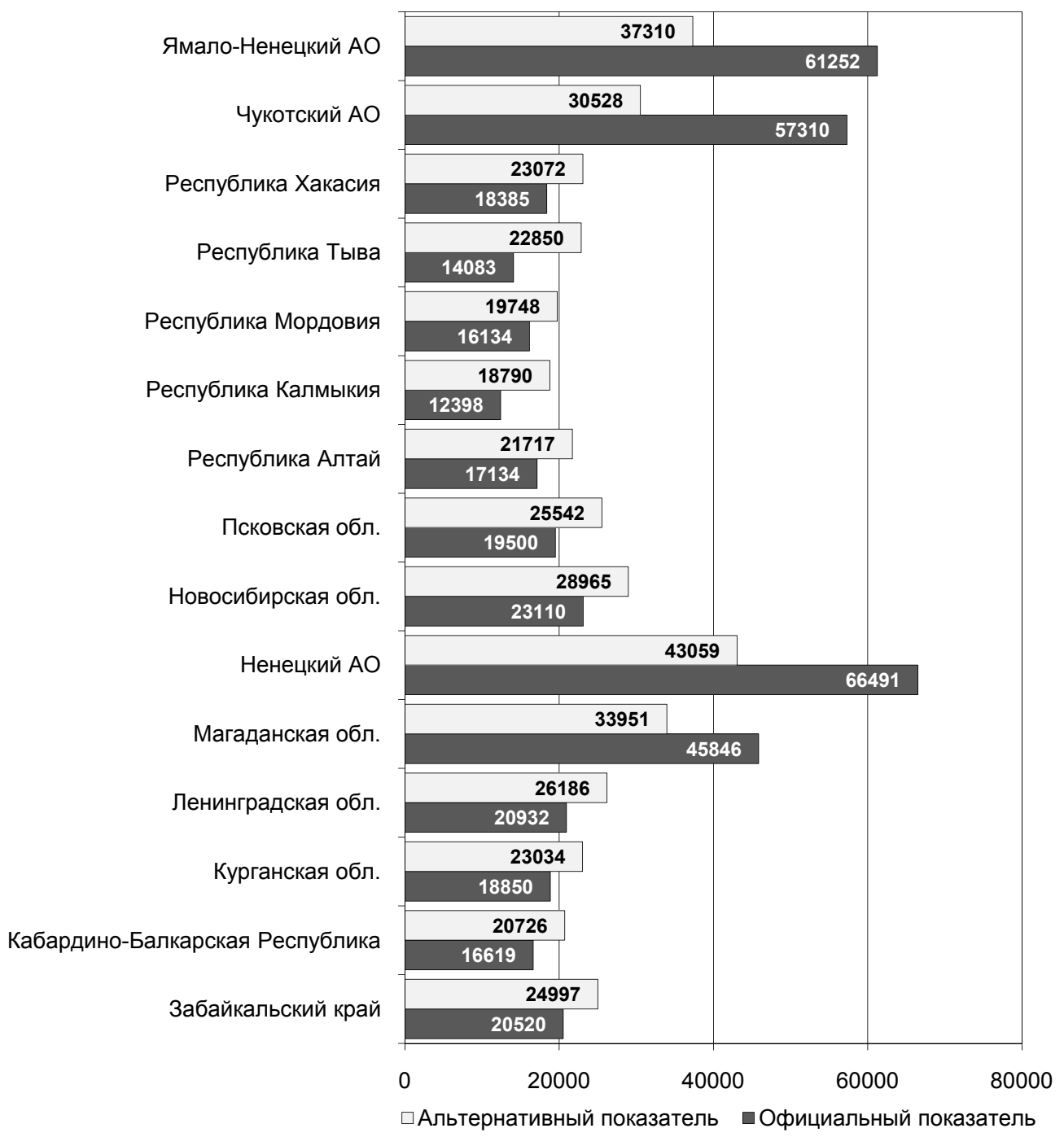

Pис.4. Альтернативная и официальная оценки дохода за 2014 г. для регионов третьей группы, руб. 
Необходимо добавить, что точность полученной альтернативной оценки душевого дохода в отдельно взятом регионе зависит от того, обладает ли этот регион специфическими особенностями, которые могут оказать воздействие на какие-либо косвенные показатели.

Например, одним из возможных объяснений, почему в Ненецком, Ямало-Ненецком, Ханты-Мансийском автономных округах и Тюменской области в целом альтернативная оценка оказалась гораздо ниже официальной, может состоять в том, что там работает большое число вахтовиков со всей страны, которые значительную часть заработанных средств тратят вне рассматриваемых регионов. В такой ситуации высокие доходы населения не обязательно отразятся, например, на стоимости квадратного метра жилья или масштабах розничной торговли, что в конечном итоге может привести к альтернативным оценкам, которые гораздо ниже официальных показателей. Сходным может быть объяснение и для таких регионов, как Магаданская, Мурманская, Сахалинская области и Республика Саха (Якутия). Заметная часть жителей этих регионов, хотя и работают здесь в течение относительно долгого времени, намереваются в итоге переехать, как там говорится, «на материк», сберегая свои доходы для будущей жизни «на материке».

Причины, по которым в ряде регионов альтернативная оценка оказалась гораздо выше официальной, например в Новосибирской и Псковской областях, пока не ясны. Необходимо детальное изучение наличия особенностей таких регионов, которые могут приводить к завышенным значениям косвенных показателей.

Вместе с тем нельзя исключить, что в регионах, в которых зафиксированы значительные расхождения между альтернативной и официальной оценками доходов, досчеты Росстата на ненаблюдаемые доходы завышают либо занижают их (или имеют место иные причины неточности статистической оценки доходов населения). Однако результаты, полученные используемым нами способом, не следует трактовать как свидетельство достоверности или недостоверности официальных данных. Наш метод лишь позволяет выделить ряд потенциальных регионов, где возможны завышения или занижения душевых доходов. Любое решение о недостоверности официальных данных в отдельно взятом регионе может быть принято только после детального анализа наличия региональных особенностей.

\section{ЗАКЛЮЧЕНИЕ}

В данной работе был предложен и реализован метод, позволяющий подойти к вопросу качества или достоверности официальных данных по доходам населения в регионах РФ с помощью количественного анализа. При- 
менение данного метода для данных за 2013 и 2014 гг. позволило получить альтернативные оценки для величины душевых доходов на основе значений косвенных показателей.

В результате применение данного метода для данных за 2013 и 2014 гг. позволило выявить ряд регионов (регионы из третьей группы), в которых возможно существенное (более $20 \%$ от официального показателя) искажение официальных статистических оценок доходов. К этим регионам относятся Тверская, Ленинградская, Новосибирская, Псковская, Саратовская области, а также Кабардино-Балкария, республики Алтай, Калмыкия, Мордовия и Тыва и др. Официальные статистические оценки доходов в данных регионах существенно отличаются от оценок, полученных по косвенным показателям.

Также было выделено множество регионов (вторая группа), о качестве данных по которым сложно сделать какие-либо выводы, так как альтернативные оценки по ним могут трактоваться по-разному. Для данных регионов полезно провести дополнительное исследование, с целью установить наличие региональных особенностей, которые могли повлиять на косвенные показатели и, соответственно, альтернативную оценку дохода.

К результатам данной работы стоит отнести также тот факт, что показатель автомобилизации, который широко используется в качестве косвенного показателя дохода (индикатора благосостояния) для международных сопоставлений, неприменим для межрегиональных сопоставлений в России, проявляя очень слабую связь с доходами населения.

Результаты, полученные в данной работе, не следует рассматривать как истину в последней инстанции. Данный метод может быть улучшен путем включения в него дополнительных (и/или исключения некоторых уже имеющихся) косвенных показателей дохода, которые позволили бы получить более точную альтернативную оценку. Еще одной доработкой могло бы послужить включение показателей, которые бы позволили учесть основные региональные особенности, например, размер региона и численность его населения, тип региона (например, ресурсодобывающий) и его географическое положение (например, Дальний Восток или Крайний Север). В качестве наиболее очевидного способа реализации этого предложения видится использование при получении альтернативной оценки для отдельного косвенного показателя не парной регрессии, а регрессии с фиктивными переменными, характеризующими наличие (или отсутствие) отдельной региональной особенности. Данная доработка позволила бы существенно снизить неточности в альтернативных оценках, которые обусловлены неучтенными региональными особенностями. 


\section{СПИСОК ЛИТЕРАТУРЫ}

1. Баранов Э.Ф. Российская статистика: достижения и проблемы // ЭКО. 2012. № 3. C. 23-34.

2. Бессонов В.А. О проблемах развития российской статистики // ЭКО. 2012. № 3. C. 35-49.

3. Глущенко К.П. Об оценке межрегионального неравенства // Пространственная экономика. 2015. № 4. С. 39-58.

4. Глущенко К.П. Исследования неравенства по доходам между российскими регионами // Регион: экономика и социология. 2010. № 4. С. 88-119.

5. Зубаревич Н.В. «Лукавые цифры» на карте Родины // ЭКО. 2012. № 4. С. 74-85.

6. Зубаревич Н.В. Неравенство доходов населения: пространственная проекция // Pro et Contra. 2013. T. 17. № 6. С. 48-60.

7. Зубаревич Н.В. Регионы России: неравенство, кризис, модернизация. М.: Независимый институт социальной политики, 2010. 160 с.

8. Зубаревич H.В. Региональная проекция нового российского кризиса // Вопросы экономики. 2015. № 4. С. 37-52.

9. Зубаревич Н.В., Сафронов С.Г. Неравенство социально-экономического развития регионов и городов России 2000-х годов: рост или снижение? // Общественные науки и современность. 2013. № 6. С. 15-26.

10. Зубаревич Н.В., Сафронов С.Г. Территориальное неравенство доходов населения России и других крупных постсоветских стран // Региональные исследования. 2014. № 4. С. 100-109.

11. Коломак E.A. Изменение межрегионального неравенства в России: анализ разных аспектов // Вестник Новосибирского государственного университета. Серия: Социально-экономические науки. 2010. Т. 10. Вып. 1. С. 78-85.

12. Рогачева O.A. О достоверности показателей доходов населения // Экономика и социум (электронное научно-практическое периодическое издание). 2012. № 3. URL: http:// www. iupr.ru (дата обращения: январь 2017).

13. Рогачева О.А. Среднедушевые денежные доходы населения: сопоставление по разным источникам // Известия Уральского государственного экономического университета. 2011. № 4. С. 83-86.

14. Россия регионов: в каком социальном пространстве мы живем? / под общ. ред. Н.В. Зубаревич. М.: Поматур, 2005. 278 с.

15. Шевяков А.Ю. Возможности и перспективы использования статистических данных в оценке масштабов скрываемых доходов // Вопросы статистики. 2003. № 6. C. 12-22.

16. Bollen K.A., Jackman R.W. Regression Diagnostics: An Expository Treatment of Outliers and Influential Cases // Modern Methods of Data Analysis. Newbury Park, CA: Sage, 1990. Pp. 257-291.

17. Cook R.D., Weisberg S. Residuals and Influence in Regression. New York; London: Chapman and Hall, 1982. 230 p.

18. Verardi V., Croux C. Robust Regression in Stata // The Stata Journal. 2009. No. 3. Pp. 439-453. 


\title{
ALTERNATIVE ESTIMATES OF PERSONAL INCOME PER CAPITA IN RUSSIAN REGIONS
}

\begin{abstract}
A.V. Yantsen
Yantsen Andrey Viktorovich - Postgraduate Student. Novosibirsk State University, 2 Pirogova Street, Novosibirsk, Russia, 630090. E-mail: andreyjanzenx@gmail.com.

Average income per capita is one of the main indicators of the standard of living. This indicator is widely used in research devoted to poverty, interregional income inequality, and is also the main reference point of success of pursued regional policies. A number of researchers note poor quality of official data on household income and call into question their reliability in some regions of Russia. The main reasons include the following: the scale of shadow economy, especially at the level of some regions; insufficient state financing of respective research; and outdated statistical methods of data processing. The author offers the method of quality checking of official statistical data on income per capita by means of a number of indirect indicators. Application of this method also allows receiving alternative estimates of the average per capita income of the population in regions of the country. On the basis of data for 2013-2014 it is shown that in a number of regions official statistical data are underestimated by more than $20 \%$. The received alternative estimates of the average per capita income can be used in further research in place of official indicators.
\end{abstract}

Keywords: alternative estimate, income per capita, indirect indicator, regions of Russia.

\section{REFERENCES}

1. Baranov E.F. Russian Statistics: Achievements and Problems. EKO - ECO, 2012, no. 3, pp. 23-34. (In Russian).

2. Bessonov V.A. On the Problems of Russia`s Statistics Development. EKO - ECO, 2012, no. 3, pp. 35-49. (In Russian).

3. Gluschenko K.P. On Estimation of Inter-Regional Inequality. Prostranstvennaya Ekonomika = Spatial Economics, 2015, no. 4, pp. 39-58. (In Russian).

4. Gluschenko K.P. Studies Inter-Regional Income Inequality in Russia. Region: Ekonomika i Sotsiologiya - Regional Research of Russia, 2010, no. 4, pp. 88-119. (In Russian).

5. Zubarevich N.V. 'Cunning Figures' on the Map of Russia. EKO-ECO, 2012, no. 4, pp. 74-85. (In Russian).

6. Zubarevich N.V. Income Inequality of the Population: Spatial Projection. Pro et Contra [Pro et Contra], 2013, vol. 17, no. 6, pp. 48-60. (In Russian).

7. Zubarevich N.V. Regions of Russia: Inequality, Crisis, Modernization. Moscow, 2010, 160 p. (In Russian).

8. Zubarevich N.V., Safronov S.G. The Inequality of Social and Economic Development of Regions and Cities of Russia of the 2000s: Growth or Decline? Obshchestvennye Nauki $i$ Sovremennost [Social Sciences and Modernity], 2013, no. 6, pp. 15-26. (In Russian).

9. Zubarevich N.V. Regional Dimension of the New Russian Crisis. Voprosy Ekonomiki [Economic Issues], 2015, no. 4, pp. 37-52. (In Russian).

10. Zubarevich N.V., Safronov S.G. Spatial Inequality of Income in Russia and Large Post-Soviet Countries. Regionalnye Issledovaniya - Regional Research, 2014, no. 4, pp. 100-109. (In Russian).

11. Kolomak E.A. Changing in Interregional Inequality in Russia: Analysis of Different Aspects. Vestnik Novosibirskogo Gosudarstvennogo Universiteta. Seriya: Sotsialno- 
Ekonomicheskie Nauki [Vestnik of Novosibirsk State University. Series: Socio-Economic Sciences], 2010, vol. 10, issue 1, pp. 78-85. (In Russian).

12. Rogacheva O.A. About Reliability of Indicators of Incomes of the Population. Ekonomika $i$ Sotsium [Economy and Society], 2012, no. 3. Available at: http:// www. iupr.ru (accessed January 2017). (In Russian).

13. Rogacheva O.A. Average Income of the Population: Comparison of Different Sources. Izvestiya Uralskogo Gosudarstvennogo Ekonomicheskogo Universiteta [News of the Ural State Economic University], 2011, no. 4, pp. 83-86. (In Russian).

14. Russia of Regions: What Social Space we Live in? Edited by N.V. Zubarevich. Moscow, 2005, 278 p. (In Russian).

15. Shevyakov A.Yu. Opportunities and Prospects of the Using of Statistical Data in the Assessment of the Extent of Concealed Income. Voprosy Statistiki [Statistical Issues], 2003, no. 6, pp. 12-22. (In Russian).

16. Bollen K.A., Jackman R.W. Regression Diagnostics: An Expository Treatment of Outliers and Influential Cases. Modern Methods of Data Analysis. Newbury Park, CA: Sage, 1990, pp. 257-291.

17. Cook R.D., Weisberg S. Residuals and Influence in Regression. New York; London: Chapman and Hall, 1982, $230 \mathrm{p}$.

18. Verardi V., Croux C. Robust Regression in Stata. The Stata Journal, 2009, no. 3, pp. $439-453$.

Для цитирования: Янцен А.B. Альтернативные оценки доходов населения в регионах России // Пространственная экономика. 2017. № 1. С. 52-70. DOI: 10.14530/ se.2017.1.052-070.

For citation: Yantsen A.V. Alternative Estimates of Personal Income Per Capita in Russian Regions. Prostranstvennaya Ekonomika = Spatial Economics, 2017, no. 1, pp. 52-70. DOI: 10.14530/se.2017.1.052-070. 